\title{
Estimated effects of the implementation of the Mexican warning labels regulation on the use of health and nutrition claims on packaged foods
}

\author{
Carlos Cruz-Casarrubias ${ }^{1}$, Lizbeth Tolentino-Mayo ${ }^{1 *}$, Stefanie Vandevijvere ${ }^{2}$ and Simón Barquera ${ }^{1}$
}

\begin{abstract}
Background: The use of health and nutrition claims on front-of-pack labels may impact consumers' food choices; therefore, many countries have established regulations to avoid misinformation. This study describes the prevalence of health and nutrition claims on the front-of-pack of food products in retail stores in Mexico and estimate the potential effects of the Official Mexican Standards 051 (new regulation that includes specifications for implementing warning labels and other packaging elements such as health and nutrition claims on less healthy foods) on the prevalence of these claims.
\end{abstract}

Methods: This is a cross-sectional study in which health and nutrition claims, nutrition information panels, and the list of ingredients of all foods and beverages available in the main retail stores in Mexico City were collected. The products were grouped by level of processing according to the NOVA food system classification. Claims were classified using the internationally harmonized INFORMAS taxonomy. According to the criteria of the new Mexican front-of-pack labelling regulation, the effect on the reduction on the prevalence of health and nutrition claims was estimated by type of food and by energy and nutrients of concern thresholds.

Results: Of 17,264 products, 33.8\% displayed nutrition claims and 3.4\% health claims. In total, $80.8 \%$ of all products in the Mexican market were classified as "less healthy"; $48.2 \%$ of products had excess calories, $44.6 \%$ had excess sodium, and $40.7 \%$ excess free sugars. The new regulation would prevent $39.4 \%$ of products with claims from displaying health and nutrition claims $(P<0.001)$; the largest reduction is observed for ultra-processed foods $(51.1 \%, P<0.001)$. The regulation thresholds that resulted in the largest reduction of claims were calories (OR $0.62, P<0.001)$ and non-sugar sweeteners (OR 0.54, $P<0.001)$.

Conclusions: The new Mexican front-of-pack labelling regulation will prevent most processed and ultra-processed foods from displaying health and nutrition claims and will potentially improve information on packaging for consumers.

Keywords: Ultra-processed foods, Nutrient profile, Health claims, Nutrition claims

\footnotetext{
* Correspondence: mltolentino@insp.mx

${ }^{1}$ Centro de Investigación en Nutrición y Salud, Instituto Nacional de Salud

Pública, Universidad No. 655, Colonia Santa María Ahuacatitlán, Cerrada Los

Pinos y Caminera. C.P, Cuernavaca, Morelos 62100, Mexico

Full list of author information is available at the end of the article
}

\section{$\triangle B M C$}

(c) The Author(s). 2021 Open Access This article is licensed under a Creative Commons Attribution 4.0 International License, which permits use, sharing, adaptation, distribution and reproduction in any medium or format, as long as you give appropriate credit to the original author(s) and the source, provide a link to the Creative Commons licence, and indicate if changes were made. The images or other third party material in this article are included in the article's Creative Commons licence, unless indicated otherwise in a credit line to the material. If material is not included in the article's Creative Commons licence and your intended use is not permitted by statutory regulation or exceeds the permitted use, you will need to obtain permission directly from the copyright holder. To view a copy of this licence, visit http://creativecommons.org/licenses/by/4.0/ The Creative Commons Public Domain Dedication waiver (http://creativecommons.org/publicdomain/zero/1.0/) applies to the data made available in this article, unless otherwise stated in a credit line to the data. 


\section{Background}

Non-communicable diseases (NCDs) contribute to more than half of the global burden of disease and unhealthy diets are one of the main risk factors for ill health [1]. In 2017, it was estimated that 11 million deaths worldwide (22\% of all deaths among adults), mainly those caused by NCDs, such as cardiovascular disease, cancers and type 2 diabetes, were attributable to unhealthy diets [2]. According to the last Mexican National Health and $\mathrm{Nu}$ trition Survey (ENSANUT by its acronym in Spanish), between 2012 and 2018 there was an increase in the prevalence of overweight and obesity in children (34.8 to $35.6 \%$ ), adolescents (34.9 to $38.4 \%$ ), and adults (71.3 to $75.2 \%$ ) [3]. The proportion of adults with type 2 diabetes also increased from 6.4 million (9.2\%) in 2012 to 8.6 million (10.3\%) in 2018 [3]. Diabetes is the main cause of disability and the third cause of mortality in Mexico [4].

The main dietary components associated with increased risk for NCDs are a high intake of sodium, added sugars, and saturated fats [5]; high levels of these nutrients are commonly found in ultra-processed foods and beverages $[6,7]$. According to the NOVA food classification (a system that categorizes foods according to the nature, extent and purpose of food processing, rather than by nutrients [8]), ultra-processed foods are ingredient formulations that result from a series of industrial processes. They generally include the addition of sugars, fats, sodium, and additives such as colorants, flavors, texturizers, humectants, and others to make them hyperpalatable; some examples are carbonated drinks, breakfast cereals, and instant soups [9]. In the Mexican population, added sugars and saturated fats contribute 12.5 and $11.2 \%$ (respectively) to total energy intake [10]. At the same time, the intake of these nutrients of concern rises with increased consumption of ultraprocessed foods and beverages [10]. The World Health Organization (WHO) recommends that free sugars should contribute less than $10 \%$ of total energy intake to prevent NCDs and ideally less than 5\% for additional health benefits [11].

Improved nutrition labelling (a description intended to inform the consumer about a food's nutritional properties) is a strategy recommended by WHO and the Pan American Health Organization (PAHO) to prevent NCDs, with the primary purpose of helping consumers make healthier food choices [12]. Nutrition labelling on the back-of-pack is often ignored by consumers or can be confusing as they generally prefer shorter and simpler messages on the front-of-pack [13, 14]. Front-of-pack labelling (FOPL) has been shown to help consumers make healthier food choices $[15,16]$. The most commonly used schemes to date include warning labels, traffic lights, the Nutri-score, and the Health Star Ratings.
Health claims ("any presentation that states, suggests or implies a relationship between a food or a constituent of that food and health") and nutrition claims ("any presentation that states, suggests or implies that a food has particular nutritional properties, including but not limited to the energy value and to the content of protein, fat and carbohydrates, as well the content of vitamins and minerals") are also ways of presenting health-related product information to consumers [17]. However, such claims constitute a form of advertising on packaging that can influence consumers' purchases (e.g. claims and product information can motivate consumers' purchasing decisions [18]), preferences (e.g. consumers interested in their health prefer products displaying health and nutrition claims (HNC) [19]), and/or consumption (e.g. nutrition claims can lead consumers to a higher energy intake because they perceive them as low calorie products [20]). Packaging displaying HNC can generate "health halos" making products look healthier regardless of their nutritional quality [21]. This can mislead consumers, who may misinterpret the nutritional quality of products with $\mathrm{HNC}[13,22]$.

Research in various countries (e.g. New Zealand [23], United Kingdom [24], Ireland [25], and Brazil [26]) shows that for some food categories (e.g. cereals, beverages and dairy products), more than half of the products display $\mathrm{HNC}$ on packaging. These studies have shown that products displaying $\mathrm{HNC}$ tend to have a more favorable nutritional profile compared to those without $\mathrm{HNC}$, although these differences were not always statistically significant. Moreover, it has been observed that in some food categories, less-healthy food products carry HNC more frequently than healthier foods [23]. Limiting the use of HNC on less-healthy foods is part of FOPL public policies. For this reason, it is important to monitor health-related labelling on food products to evaluate compliance with these policies [27]. Therefore, the International Network of Food and Obesity, NCDs Research, Monitoring and Action Support (INFORMAS) developed specific protocols for monitoring different types of $\mathrm{HNC}$ on food products, using a common taxonomy and harmonized methodology across countries [27, 28].

Some regions and countries in the world such as Australia and New Zealand have adopted specific regulations for the use of HNC on food products, including a series of nutritional criteria/thresholds that foods must pass in order to carry HNC [29]. However, nutrient profile models (algorithms for classifying foods and beverages according to their nutritional composition to promote public health dietary goals [30]) that are designed to prevent less-healthy food products from carrying claims only apply to health claims, not to nutrition claims, which are generally more common [29]. In March 2020, the Mexican FOPL system "Guideline Daily 
Amounts (GDA)", which has been shown to be very confusing for consumers [31], was replaced by a warning label system. This label system is mandatory and includes warnings for calories, added sugar, saturated fat, trans fat and sodium [32]. This regulation went into effect in October 2020, although the thresholds for energy and nutrients of concern will become progressively stricter over 5 years. The specifications of the new regulation are found in the Official Mexican Standards 051 (NOM-051 for its acronym in Spanish), and aims to improve the information located on packaging for consumers; in addition, other elements such as advertising directed at children and the use of HNC on less-healthy foods and beverages will be regulated beginning in July 2021.

Unlike other countries that have implemented warning labels to date, such as Chile, Peru and Uruguay, the Mexican warning label system includes statements about certain additives that are not recommended for children, such as non-sugar sweeteners (artificial or natural noncaloric sweeteners or caloric sweeteners like polyols) and caffeine. In addition, the nutrient profile used by the Mexican regulation is based on the PAHO Nutrient Profile Model, which is more restrictive than the nutrient profile model used by Chile, Peru and Uruguay as it classifies all ultra-processed food products as less-healthy [33]. Food products with at least one warning label or warning legend must not display HNC on the front-ofpack.

This new public policy could prevent most of lesshealthy packaged foods and beverages (specially ultraprocessed foods) from including misleading information for consumers. However, it is unclear what impact the new Mexican FOPL regulation would have on the prevalence of $\mathrm{HNC}$ on less-healthy products.

The objectives of this study were to comprehensively measure the prevalence of $\mathrm{HNC}$ on the front-of-pack of foods and beverage products in the Mexican market and to estimate the potential effects of the new regulation on the prevalence of HNC on processed and ultraprocessed food products.

\section{Methods}

This is a cross-sectional study that analyzed the prevalence of HNC on the front-of-pack of foods and beverages available in retail stores in Mexico City during the period of January to March 2017. The retail stores were selected randomly and included the biggest supermarket chains in Mexico (such as the Walmart group, La Comer, Soriana, and Chedraui) and other types of retail stores. The selection of retail stores was made according to the urban Basic Geostatistics Areas (AGEB by its acronym in Spanish; it is a geographical area delimited by streets, avenues, walkways, or any other feature whose land use is dedicated to living, industrial, or commercial usage and its population is greater than 2500 inhabitants). The selection of AGEBs was determined according to the level of marginalization defined by the National Institute of Statistics and Geography (a Mexican sociodemographic indicator that considers the infrastructure for access to basic household services, health services, and education to measure the social disadvantages of AGEBs in three levels: low, middle, and high [34]) and population density ( $>20$, 000 inhabitants). The selection of retail stores in each AGEB were selected randomly and proportionate to size.

Data were collected from 136 retail stores of different types: supermarkets $(n=52)$, price club $(n=8$, a type of supermarket where membership is required, and which generally offers products contained in multi-packages for consumers and other establishments), wineries ( $n=$ $32)$, convenience stores $(n=20)$, mini supermarkets $(n=17)$, and other types of retail stores $(n=7)$. The selected retail stores included supermarket chains with more than $70 \%$ of the market share in Mexico [35].

To collect data, nutrition undergraduate students were trained by researchers from the National Institute of Public Health (INSP). Photographs were taken of each side of the package with a smartphone. When a product had a singular shape (cylinder, sphere or bag), the fieldworkers captured all relevant information. The following information was captured: Name of the product, the front of the package (including $\mathrm{HNC}$ ), the type of package, GDA labelling, bar code, list of ingredients, nutrient facts table, and price. The fieldworkers walked through all the aisles of the retail stores to capture all products available (except products that were repeated/duplicated in different stores). Bar codes were used to identify duplicate products. Each field worker collected information on the same category of products from all included retail stores. Before taking photographs, we consulted the legal representatives of each store and/or the manager in charge for authorization.

Relevant information on food and beverage packages (as detailed below) was captured in REDCaP (Research Electronic Data Capture, an application for management of electronic data) by eight previously trained research assistants and exported in electronic spreadsheets.

\section{Health and nutrition claims}

All claims that appeared on FOPL were registered and classified according to the INFORMAS protocols and taxonomy (Table 1) $[27,28]$. The classification included three categories and their subcategories (see Additional file 1): 1) Nutrition claims (health-related ingredients claim, nutrient content claim, and nutrient comparative), 2) Health claims (general health claim, nutrient and other function claim, and reduction of disease risk claim), and 3) Other claims (i.e. organic, gluten free). The format of each claim 
Table 1 Examples of different types of health and nutrition claims according to the INFORMAS taxonomy [27, 28]

\begin{tabular}{lll}
\hline Claim & Types of claims & Examples \\
\hline Nutrition claim & Health-related ingredient claim & $\begin{array}{c}\text { "Contains 25\% orange juice" } \\
\text { "Contains whole grains" }\end{array}$ \\
& Nutrient content claim & "Low calories" \\
"Contains calcium" & "Light" \\
"Sweetened with stevia" & "Low glycemic index" \\
"Health claim & Nutrient comparative claim & "Calcium for strong bones" \\
& General health claim & "Magnesium for growth" \\
& Nutrient and other function claim & "Pediatric heart association" \\
"Prevents cavities" & "Organic" \\
"Non-GMO"
\end{tabular}

INFORMAS International Network for Food and Obesity/non-communicable Diseases Research, Monitoring and Action Support. GMO Genetically

Modified Organisms

was also recorded as verbal, numerical or symbolic. Products containing combinations of numerical and verbal formats were registered as numerical.

\section{Food groups}

Food and beverages were grouped according to their degree of processing according to the NOVA classification system (a system to classify food and beverages according to the extent and purpose of food processing); this allows us to identify ultra-processed foods, which are commonly targeted in regulations related to FOPL, taxes and advertising directed to children. Food and beverages were classified as unprocessed or minimally processed foods (such as fresh fruits or vegetables, whole grain cereals, plain milk, and seeds with no added ingredients), processed culinary ingredients (such as salt, sugar or oil), processed foods (such as canned fruits and vegetables, salted seeds or meat with salt for preservation), and ultra-processed foods (such as carbonated beverages, ready to eat foods like pizza or hamburgers, pastries and breakfast cereals) [8]. The classification was made using the information available in the nutrition information panel and list of ingredients such as sugars, sodium, fat and added sweeteners, and others like emulsifiers, preservatives, binders, humectants, stabilizers, brighteners, colorants, and flavorings.

\section{Nutritional quality}

Nutritional quality of the food products was calculated using the nutrient profile criteria of the Mexican FOPL regulation. Energy information was reported in calories, saturated fats, trans fats, and free sugars (such as sugar, sucrose, fructose, corn syrup, honey, and fruit juice) in grams per $100 \mathrm{~g} / \mathrm{mL}$, sodium in milligrams per $100 \mathrm{~g} /$ $\mathrm{mL}$, and use of non-sugar sweeteners reported in the list of ingredients. For products that require preparation prior to consumption, the reconstituted content was considered. This nutrient profile is applicable to products containing added sugar, sodium or fat $(n=14,191)$, so unprocessed or minimally processed foods and processed culinary ingredients were automatically classified without excess nutrients of concern (healthier). To establish the cut-off points, the calories per gram were calculated for free sugars ( $4 \mathrm{kcal})$, saturated fats $(9 \mathrm{kcal})$, and trans fats $(9 \mathrm{kcal})$. The following criteria of the Mexican FOPL regulation were applied [32]: Excess of: a) calories: $\geq 275 \mathrm{kcal}$ per $100 \mathrm{~g}$ for foods, $\geq 70 \mathrm{kcal}$ per $100 \mathrm{~mL}$ for beverages or $\geq 8 \mathrm{kcal}$ per $100 \mathrm{~mL}$ from free sugars for beverages; b) free sugars: $\geq 10 \%$ of total energy from free sugars; c) saturated fat: $\geq 10 \%$ of total energy from saturated fat; d) trans fat: $\geq 1 \%$ of total energy from trans fat; e) sodium: $\geq 1 \mathrm{mg}$ of sodium per $1 \mathrm{kcal}$ or $\geq 300 \mathrm{mg}$ per $100 \mathrm{~g}, \geq 45 \mathrm{mg}$ per $100 \mathrm{~mL}$ for noncaloric beverages; and use of non-sugar sweeteners: reported in list of ingredients. For products without disaggregated content of free sugars on the package, we calculated free sugars according to the algorithms proposed by the PAHO nutrient profile model (see Additional file 2) [5].

\section{Scenarios for the use of health and nutrition claims}

Two scenarios were applied to show the differences in the use of HNC before and after the implementation of the regulation.

The first scenario (current scenario) analyzes the prevalence of $\mathrm{HNC}$ on packaged food products in Mexico in 2017. The second scenario (regulatory scenario) was established following the specifications of the third and final stage of the new FOPL regulation in Mexico. The regulation requires that products with warning labels (excessive in calories, free sugars, saturated fats, trans fats and sodium) or warning legends 
(contains non-sugar sweeteners or added caffeine) must not [32]: a) use health claims, b) use nutrition claims, or c) display nutrition claims on the FOPL.

The following types of claims are considered in the regulation: Nutrient content claim, nutrient comparative claim, nutrient and other function claim, and reduction of disease risk claim. Consequently, these types of claims were covered in the analyses for the second scenario (Table 5 and Table 6). For health-related ingredient claims and general health claims (as per the INFORMAS taxonomy), the Mexican regulations do not apply.

We used the nutrient profile criteria of the Mexican FOPL regulation to determine which products are still allowed to display HNC.

\section{Statistical analysis}

The analyses were performed using the statistical package STATA version 14 . To verify the consistency in the classification of claims, we performed a reliability test between two raters (Table 2). A random sample of products that contained claims $(n=436)$ was taken and claims were classified according to the content and format by the two raters. The proportions of claims classified by category and subcategories were compared. The consistency in the reliability tests was determined using the Kappa Coefficient; values above 0.8 indicate very good consistency. The variables included in the analysis correspond to the categorical type, so they were presented as frequencies and percentages. The use of $\mathrm{HNC}$ was presented by food group, claim type (Table 4), and nutrient profile (Table 6). Chi-square tests were used to determine differences in the proportion of products with HNC between the current scenario and the regulatory scenario (Table 5 and Table 6). Two logistic regression models were fitted to determine the Odds Ratio (OR) of
HNC prevalence in the current scenario and the regulatory scenario. Both models were adjusted for the components of the Mexican FOPL regulation and we report the results for each threshold of the nutrient profile separately. The analysis that included the regulatory scenario only considered products with claims $(n=8746)$. For all tests, the value $P<0.05$ was considered as statistically significant.

\section{Results}

In general, there were no statistically significant differences between both raters in the proportion of each type of claim classified by food category and subcategory $(P>0.05)$. There was good agreement between raters for classification by categories and subcategories of claims $(\mathrm{K}>0.8)$ (Table 2).

Photographs of 18,558 unique products were collected. Products contained in multi-packages $(n=533)$ and those with inconsistencies in nutritional information ( $n=761$ ) were excluded (for example, differences of more than $15 \%$ between reported and calculated calorie content, portion size, and sum of nutrients and units of nutrients). In total, 17,264 food and beverage packages available in retail stores in Mexico were included, of which, $72 \%$ were classified as ultra-processed foods, $10.4 \%$ as unprocessed or minimally processed foods, 9.9\% as processed foods, and $7.4 \%$ as processed culinary ingredients. When evaluating the nutritional quality of all included products, $48.2 \%$ of food products were excessive in calories, $44.6 \%$ were excessive in sodium, and $40.7 \%$ were excessive in free sugars according to the thresholds of the Mexican FOPL regulation. For processed foods, $69.2 \%$ were excessive in sodium and $41.4 \%$ were excessive in calories; most of the ultra-processed foods were excessive in calories $(61.0 \%)$ and free sugars $(53.4 \%)$ (Table 3$)$.

Table 2 Inter-rater reliability for the classification of claims according to the INFORMAS taxonomy $(n=436)$

\begin{tabular}{|c|c|c|c|c|c|c|}
\hline & \multicolumn{2}{|c|}{ Rater 1} & \multicolumn{2}{|c|}{ Rater 2} & \multirow[t]{2}{*}{$P$-Value } & \multirow[t]{2}{*}{$\mathrm{K}$} \\
\hline & $\mathrm{n}$ & $\%$ & $\mathrm{n}$ & $\%$ & & \\
\hline Health-related ingredient claim & 60 & 13.8 & 61 & 14.0 & 0.992 & 0.8744 \\
\hline Nutrient content claim & 158 & 36.2 & 159 & 36.5 & 0.955 & 0.9314 \\
\hline Nutrient comparative claim & 40 & 9.2 & 44 & 10.1 & 0.889 & 0.9039 \\
\hline General health claim & 21 & 4.8 & 20 & 4.6 & 0.975 & 0.8775 \\
\hline Nutrient and other function claim & 4 & 0.9 & 3 & 0.7 & - & - \\
\hline Reduction of disease risk claim & 11 & 2.5 & 12 & 2.8 & - & - \\
\hline Environmental & 245 & 56.2 & 247 & 56.7 & 0.911 & 0.9656 \\
\hline Other & 163 & 37.4 & 165 & 37.8 & 0.940 & 0.9494 \\
\hline Numerical & 78 & 17.9 & 99 & 22.7 & 0.433 & 0.8163 \\
\hline Verbal & 211 & 48.4 & 216 & 49.5 & 0.820 & 0.8258 \\
\hline Symbolic & 335 & 76.8 & 329 & 75.5 & 0.694 & 0.8743 \\
\hline
\end{tabular}

$P$-value for difference between two proportions. K Cohen's Kappa Coefficient 
Table 3 Proportion of label components, claims and nutrient profile $(n=17,264)$, the Mexican food supply, 2017

\begin{tabular}{|c|c|c|c|c|c|c|c|c|c|c|}
\hline & \multicolumn{2}{|l|}{ Total } & \multicolumn{2}{|c|}{$\begin{array}{l}\text { Unprocessed or } \\
\text { minimally } \\
\text { processed foods } \\
(n=1794)\end{array}$} & \multicolumn{2}{|c|}{$\begin{array}{l}\text { Processed culinary } \\
\text { ingredients } \\
(n=1279)\end{array}$} & \multicolumn{2}{|c|}{$\begin{array}{l}\text { Processed } \\
\text { foods } \\
(n=1705)\end{array}$} & \multicolumn{2}{|c|}{$\begin{array}{l}\text { Ultra-processed } \\
\text { foods } \\
(n=12,486)\end{array}$} \\
\hline & $\mathbf{n}$ & $\%$ & $\mathbf{n}$ & $\%$ & $\mathbf{n}$ & $\%$ & $\mathbf{n}$ & $\%$ & $\mathbf{n}$ & $\%$ \\
\hline \multicolumn{11}{|l|}{ Mexican FOPL nutrient profile } \\
\hline Passes nutrient profile & 3403 & 19.7 & 1794 & 100 & 1279 & 100 & 88 & 5.2 & 242 & 1.9 \\
\hline $\begin{array}{l}\text { Excessive in one or more nutrients of } \\
\text { concern or energy }\end{array}$ & 13,861 & 80.3 & 0 & 0 & 0 & 0 & 1617 & 94.8 & 12,244 & 98.1 \\
\hline Excessive in calories & 8327 & 48.2 & 0 & 0 & 0 & 0 & 706 & 41.4 & 7621 & 61.0 \\
\hline Excessive in free sugars & 7020 & 40.7 & 0 & 0 & 0 & 0 & 351 & 20.6 & 6669 & 53.4 \\
\hline Excessive in sodium & 7699 & 44.6 & 0 & 0 & 0 & 0 & 118 & 69.2 & 6519 & 52.2 \\
\hline Excessive in saturated fats & 6054 & 36.1 & 0 & 0 & 0 & 0 & 518 & 32.4 & 5536 & 45.8 \\
\hline Excessive in trans fats & 156 & 2.1 & 0 & 0 & 0 & 0 & 17 & 4.1 & 139 & 3.7 \\
\hline Containing non-sugar sweeteners & 2176 & 12.6 & 0 & 0 & 0 & 0 & 0 & 0 & 2176 & 17.4 \\
\hline \multicolumn{11}{|l|}{ Label Components } \\
\hline List of ingredients & 16,745 & 97.0 & 1472 & 82.1 & 1181 & 92.3 & 1659 & 97.4 & 12,433 & 99.6 \\
\hline Nutrient declarations & 17,242 & 99.8 & 1793 & 99.9 & 1279 & 100 & 1705 & 100 & 12,465 & 99.8 \\
\hline \multicolumn{11}{|l|}{ Supplementary nutrition information } \\
\hline GDA & 13,598 & 78.8 & 1215 & 67.7 & 882 & 69 & 1359 & 79.7 & 10,142 & 81.2 \\
\hline Sello Nutrimental & 18 & 0.1 & 3 & 0.2 & 6 & 0.5 & 2 & 0.1 & 7 & 0.1 \\
\hline \multicolumn{11}{|l|}{ Use of claims } \\
\hline Yes & 8746 & 50.7 & 1036 & 57.8 & 598 & 46.8 & 673 & 39.5 & 6439 & 51.6 \\
\hline No & 8518 & 49.3 & 758 & 42.2 & 681 & 53.2 & 1032 & 60.5 & 6047 & 48.4 \\
\hline Nutrition claim & 5839 & 33.8 & 746 & 41.6 & 296 & 23.1 & 299 & 17.5 & 4498 & 36.0 \\
\hline Health-related ingredient claim & 1614 & 9.4 & 209 & 11.7 & 124 & 9.7 & 59 & 3.5 & 1222 & 9.8 \\
\hline Nutrient content claim & 4667 & 27.0 & 660 & 36.8 & 184 & 14.4 & 247 & 14.5 & 3576 & 28.6 \\
\hline Nutrient comparative claim & 998 & 5.8 & 45 & 2.5 & 61 & 4.8 & 27 & 1.6 & 865 & 6.9 \\
\hline Health claims & 617 & 3.4 & 74 & 4.1 & 80 & 6.3 & 22 & 1.3 & 441 & 3.5 \\
\hline General health claim & 306 & 1.8 & 60 & 3.3 & 68 & 5.3 & 12 & 0.7 & 166 & 1.3 \\
\hline Nutrient and other function claim & 145 & 0.8 & 4 & 0.2 & 7 & 0.6 & 6 & 0.4 & 128 & 1.0 \\
\hline Reduction of disease risk claim & 214 & 1.2 & 12 & 0.7 & 14 & 1.1 & 4 & 0.2 & 184 & 1.5 \\
\hline Other claim & 5190 & 30.1 & 616 & 34.3 & 476 & 37.2 & 553 & 32.4 & 3545 & 28.4 \\
\hline
\end{tabular}

GDA Guide Daily Amount. Sello Nutrimental is a type of voluntary labelling to indicate that food and beverages are healthy

More than half of all products (50.7\%) displayed claims on the FOPL. Nutrition claims were the most frequent type of claims $(33.8 \%)$, mainly nutrient content claims (27\%). In terms of claim format, symbolic claims were the most frequently used (33.9\%). Table 4 shows the proportion of products with claims by food group. The category of unprocessed or minimally processed foods had the highest proportion of products with claims, mainly plain milk (97.4\%), juices and fruit drinks (77.1\%), and purees of fruits, vegetables and cereals (76.4\%). More than half of the ultra-processed food products displayed at least one claim (51.6\%); claims were found most frequently for baby food (92.2\%), breakfast cereals (82.2\%), and yogurt and milk-based beverages (67.5\%). Among products with claims, nutrition claims were common for unprocessed or minimally processed (72\%) and ultra-processed foods (69.9\%).

In the current scenario, $68.4 \%$ (95\% CI 67.4-69.3) of all products and $71.0 \%$ (95\% CI $69.8-72.1)$ of ultraprocessed foods displayed $\mathrm{HNC}$ on the front-of-package (Table 5). This proportion is highest for beverages with non-sugar sweeteners (96.7, 95\% CI 95.0-98.0) and baby food (93.0, 95\% CI 88.6-96.1). In the regulatory scenario, the proportion of all products that would display HNC is significantly lower $(39.4 \%, P<0.001,95 \%$ CI $38.1-$ 40.8) compared to the current scenario. The differences were statistically significant for all food and beverage categories. The largest reduction in the prevalence of 
Table 4 Proportion of packaged food products with claims according to the NOVA food groups

\begin{tabular}{|c|c|c|c|c|c|}
\hline & $\mathbf{n}$ & Use of Claims (\%) & Nutrition claims (\%) & Health Claims (\%) & Other claims (\%) \\
\hline Total & 17,264 & 50.7 & 66.8 & 7.1 & 59.3 \\
\hline Unprocessed or minimally processed foods & 1794 & 57.8 & 72.0 & 7.1 & 59.5 \\
\hline Milk & 113 & 97.4 & 100 & 10.9 & 36.4 \\
\hline Cereals & 218 & 46.8 & 66.7 & 8.8 & 75.5 \\
\hline Fruits and vegetables & 277 & 54.5 & 37.1 & 17.2 & 76.8 \\
\hline Legumes & 87 & 9.2 & 62.5 & 0 & 37.5 \\
\hline Coffee and tea & 135 & 62.2 & 57.1 & 7.1 & 71.4 \\
\hline Eggs, read meat and seafood & 90 & 50.0 & 40.0 & 4.4 & 91.1 \\
\hline Water & 109 & 51.4 & 85.7 & 14.3 & 30.4 \\
\hline Juices and fruit drinks & 166 & 77.1 & 85.9 & 0.8 & 71.9 \\
\hline Nuts and seeds & 126 & 61.9 & 74.4 & 3.9 & 73.1 \\
\hline Pastas & 401 & 54.6 & 81.3 & 3.2 & 34.3 \\
\hline Puree of fruits, vegetables and cereals & 72 & 76.4 & 85.5 & 0 & 69.1 \\
\hline Processed culinary ingredients & 1279 & 46.8 & 49.5 & 13.4 & 79.6 \\
\hline Oils and fats & 336 & 45.5 & 62.8 & 17.7 & 62.8 \\
\hline Dressings & 315 & 51.8 & 34.4 & 13.5 & 92.0 \\
\hline Condiments & 183 & 27.9 & 52.9 & 5.9 & 76.5 \\
\hline Sweeteners & 445 & 51.9 & 50.7 & 12.1 & 82.7 \\
\hline Processed foods & 1705 & 39.5 & 44.4 & 3.3 & 82.2 \\
\hline Fruits and vegetables (canned) & 526 & 39.5 & 13.5 & 2.9 & 94.7 \\
\hline Meat and seafood & 298 & 41.3 & 69.9 & 3.3 & 75.6 \\
\hline Sweet snacks & 152 & 28.3 & 46.5 & 9.3 & 69.8 \\
\hline Salty snacks & 348 & 35.6 & 65.3 & 1.6 & 71.0 \\
\hline Bread and other cereals & 152 & 56.6 & 66.3 & 7.0 & 76.7 \\
\hline Cheeses & 128 & 29.7 & 47.4 & 0 & 76.3 \\
\hline Other ${ }^{a}$ & 101 & 50.5 & 17.7 & 0 & 98.0 \\
\hline Ultra-processed foods & 12,486 & 51.6 & 69.9 & 6.9 & 55.1 \\
\hline Yogurt and milk-based beverages & 935 & 67.5 & 91.6 & 10.9 & 34.4 \\
\hline Ultra-processed meat & 649 & 67.3 & 29.5 & 3.9 & 98.4 \\
\hline Breakfast cereals & 555 & 82.2 & 83.8 & 11.0 & 48.7 \\
\hline Seafood & 208 & 36.1 & 81.3 & 9.3 & 50.7 \\
\hline Beverages with non-sugar sweeteners ${ }^{b}$ & 948 & 67.5 & 96.6 & 8.8 & 19.2 \\
\hline Sugar-Sweetened beverages ${ }^{c}$ & 775 & 54.1 & 74.0 & 10.0 & 49.2 \\
\hline Sweet snacks ${ }^{d}$ & 3956 & 44.2 & 67.7 & 3.0 & 57.7 \\
\hline Salty snacks & 912 & 35.8 & 58.6 & 2.8 & 70.6 \\
\hline Packaged bread and tortilla & 215 & 65.6 & 75.2 & 8.5 & 46.1 \\
\hline Cheeses & 360 & 31.9 & 64.4 & 7.0 & 52.2 \\
\hline Ready to eat & 409 & 40.3 & 37.0 & 3.0 & 87.9 \\
\hline Baby food & 218 & 92.2 & 88.1 & 13.9 & 39.8 \\
\hline Soups pastas and creams & 326 & 60.4 & 50.8 & 1.0 & 71.6 \\
\hline Other $^{\mathrm{e}}$ & 2020 & 43.9 & 59.4 & 9.4 & 65.2 \\
\hline
\end{tabular}

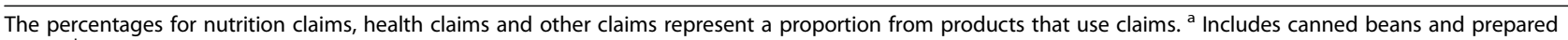
salads, ${ }^{b}$ includes beverages sweetened with artificial or natural non-caloric sweeteners or polyols, ${ }^{c}$ Includes nectars, fruit drinks with added sugar, energy drinks, sport drinks and powder to prepare beverages, ${ }^{\mathrm{d}}$ Includes candies, sweets, desserts and bakery, ${ }^{\mathrm{e}}$ Includes prepared flour bakery, prepared cereals, non-sugar sweeteners and ultra-processed culinary ingredients (margarine, seasonings for meat) 
Table 5 Difference between current scenario and regulatory scenario for the prevalence of health and nutrition claims ( $n=8746$ )

\begin{tabular}{|c|c|c|c|c|c|c|c|}
\hline & \multirow[b]{3}{*}{$\mathbf{n}$} & \multicolumn{4}{|c|}{ Proportion of products with health and nutrition claims } & \multirow{2}{*}{\multicolumn{2}{|c|}{ Difference }} \\
\hline & & \multicolumn{2}{|c|}{ Current scenario } & \multicolumn{2}{|c|}{ Regulatory scenario } & & \\
\hline & & $\%$ & $95 \% \mathrm{Cl}$ & $\%$ & $95 \% \mathrm{Cl}$ & $\%$ & $95 \% \mathrm{Cl}$ \\
\hline All products with claims & 8746 & 68.4 & {$[67.4,69.3]$} & 28 & {$[27.1,29.0]$} & $39.4^{* * *}$ & {$[38.1,40.8]$} \\
\hline Processed and ultra-processed foods & 7112 & 68.6 & {$[67.3,69.9]$} & 19.1 & {$[17.0,21.2]$} & $49.5^{* * *}$ & {$[47.1,51.2]$} \\
\hline Processed foods & 673 & 46.2 & {$[42.4,50.1]$} & 11.0 & {$[8.7,13.6]$} & $35.2^{* * *}$ & {$[30.8,39.7]$} \\
\hline Fruits and vegetables (canned) & 208 & 14.4 & {$[9.9,19.9]$} & 9.6 & {$[6.0,14.5]$} & $4.8^{* * *}$ & {$[0.1,11.0]$} \\
\hline Meat and seafood & 123 & 72.4 & {$[63.6,80.0]$} & 7.3 & {$[3.4,13.4]$} & $65.0^{* * *}$ & {$[55.9,74.2]$} \\
\hline Sweet snacks & 43 & 51.2 & {$[35.5,66.7]$} & 2.3 & {$[0.1,12.3]$} & $48.8^{* * *}$ & {$[33.2,64.4]$} \\
\hline Salty snacks & 124 & 66.9 & {$[57.9,75.1]$} & 8.9 & {$[4.5,15.3]$} & $58.1^{* * *}$ & {$[48.4,67.7]$} \\
\hline Bread and other cereals & 86 & 69.8 & {$[58.9,79.2]$} & 25.6 & {$[16.8,36.1]$} & $44.2^{* * *}$ & {$[30.8,57.6]$} \\
\hline Cheeses & 38 & 47.4 & {$[31.0,64.2]$} & 23.7 & {$[11.4,40.2]$} & $23.7^{*}$ & {$[0.3,44.5]$} \\
\hline Other ${ }^{a}$ & 51 & 17.7 & {$[8.4,30.9]$} & 3.9 & {$[0.5,13.5]$} & $13.7^{*}$ & {$[0.2,25.5]$} \\
\hline Ultra-processed foods & 6439 & 71.0 & {$[69.8,72.1]$} & 19.9 & {$[19.0,20.9]$} & $51.1 * * *$ & {$[49.5,52.5]$} \\
\hline Yogurt and milk-based beverages & 631 & 92.6 & {$[90.2,94.5]$} & 26.3 & {$[22.9,29.9]$} & $66.2^{* * *}$ & {$[62.2,70.2]$} \\
\hline Ultra-processed meat & 437 & 31.1 & {$[26.8,35.7]$} & 5.3 & {$[3.4,7.8]$} & $25.9 * * *$ & {$[21.4,30.7]$} \\
\hline Breakfast cereals & 456 & 85.8 & {$[82.2,88.8]$} & 47.8 & {$[43.1,52.5]$} & $37.9^{* * *}$ & {$[32.3,43.5]$} \\
\hline Seafood & 75 & 89.3 & {$[80.1,95.3]$} & 9.3 & {$[3.8,18.3]$} & $80.0^{* * *}$ & {$[70.4,89.6]$} \\
\hline Beverages with non-sugar sweeteners ${ }^{b}$ & 640 & 96.7 & {$[95.0,98.0]$} & 10.8 & {$[8.5,13.4]$} & $85.9^{* * *}$ & {$[83.2,88.7]$} \\
\hline Sugar-Sweetened beverages ${ }^{c}$ & 419 & 75.2 & {$[70.8,79.2]$} & 19.6 & {$[15.9,23.7]$} & $55.6^{* * *}$ & {$[50.0,61.2]$} \\
\hline Sweet snacks ${ }^{d}$ & 1750 & 68.0 & {$[65.8,70.2]$} & 20.3 & {$[18.5,22.3]$} & $47.7^{* * *}$ & {$[44.8,50.5]$} \\
\hline Salty snacks & 326 & 58.9 & {$[53.3,64.3]$} & 6.8 & {$[4.3,10.0]$} & $52.1^{* * *}$ & {$[46.2,58.1]$} \\
\hline Packaged bread and tortilla & 141 & 75.2 & {$[67.2,82.1]$} & 31.9 & {$[24.3,40.3]$} & $43.3^{* * *}$ & {$[32.8,53.8]$} \\
\hline Cheeses & 115 & 66.1 & {$[56.7,74.7]$} & 27.8 & {$[19.9,37.0]$} & $38.3^{* * *}$ & {$[26.3,50.2]$} \\
\hline Ready to eat & 165 & 38.8 & {$[31.3,46.7]$} & 15.8 & {$[10.6,22.2]$} & $23.0^{* * *}$ & {$[13.7,32.3]$} \\
\hline Baby food & 201 & 93.0 & {$[88.6,96.1]$} & 36.3 & {$[29.7,43.4]$} & $56.7^{* * *}$ & {$[49.2,64.2]$} \\
\hline Soups pastas and creams & 197 & 51.3 & {$[44.1,58.4]$} & 14.2 & {$[9.7,19.9]$} & $37.1^{* * *}$ & {$[28.5,45.6]$} \\
\hline Other $^{e}$ & 886 & 61.1 & {$[57.8,64.3]$} & 15.5 & {$[13.1,18.0]$} & $45.9^{* * *}$ & {$[41.6,49.6]$} \\
\hline
\end{tabular}

Only includes products with claims.

ancludes canned beans and prepared salads,

${ }^{b}$ includes beverages sweetened with artificial or natural non-caloric sweeteners or polyols,

Includes nectars, fruit drinks with added sugar, energy drinks, sport drinks and powder to prepare beverages,

dincludes candies, sweets, desserts and bakery,

e Includes prepared flour bakery, prepared cereals, non-sugar sweeteners and ultra-processed culinary ingredients (margarine, seasonings for meat). The proportion of products with health and nutrition claims in the regulatory scenario was estimated according to the nutrient profile thresholds of the new Mexican food labelling regulation (third stage). The regulatory scenario does not affect the proportion of products with health and nutrition claims of unprocessed or minimally processed foods and culinary ingredients. Chi-squared test, the proportion values were significantly different between current scenario and regulatory scenario: ${ }^{*}(P<0.05),{ }^{* * *}(P<0.001)$

HNC was observed for ultra-processed foods, where the regulatory scenario would prevent $51.1 \%(P<0.001,95 \%$ CI 49.5-52.5) of these products from displaying HNC. Within the category of ultra-processed products, the highest reduction in the prevalence of HNC was observed in beverages with non-sugar sweeteners $(85.9 \%$, $P<0.001,95 \%$ CI 82.3-88.7).

In Table 6, we compared the proportion of products with HNC between the current scenario and the regulatory scenario according to the thresholds for energy and nutrients of concern as per the Mexican regulations. In the current scenario, $94.9 \%$ of the products containing non-sugar sweeteners displayed HNC on the FOPL. According to other thresholds, $65.5 \%$ of products excessive in saturated fats, $69.4 \%$ of products excessive in free sugars, and $70.1 \%$ of those excessive in calories displayed HNC. Products that were excessive in calories were 1.40 $(P<0.001,95 \%$ CI $1.25-1.56)$ times more likely to display $\mathrm{HNC}$, compared to products that were not excessive in calories in the current scenario (versus 0.6 times more likely in the regulatory scenario). The Odds Ratio was highest for comparing products that contained nonsugar sweeteners versus those that did not contain such sweeteners (OR 11.67, $P<0.001,95 \%$ CI 9.14-14.88). In 
Table 6 Difference in scenarios for the prevalence of health and nutrition claims on less healthy products

\begin{tabular}{|c|c|c|c|c|c|c|c|c|c|}
\hline & \multirow{3}{*}{$\mathbf{n}$} & \multicolumn{4}{|c|}{$\begin{array}{l}\text { Proportion of products with } \\
\text { health and nutrition claims }\end{array}$} & \multicolumn{4}{|c|}{$\begin{array}{l}\text { Odds Ratio for the use of } \\
\text { health and nutrition claims }\end{array}$} \\
\hline & & \multicolumn{2}{|c|}{ Current scenario } & \multicolumn{2}{|c|}{ Regulatory scenario } & \multicolumn{2}{|c|}{ Current scenario } & \multicolumn{2}{|c|}{ Regulatory scenario } \\
\hline & & $\%$ & $95 \% \mathrm{Cl}$ & $\%$ & $95 \% \mathrm{Cl}$ & OR & $95 \% \mathrm{Cl}$ & $\overline{\mathrm{OR}}$ & $95 \% \mathrm{Cl}$ \\
\hline Excessive in calories & 3957 & 70.1 & {$[68.7,71.5]$} & $20.6^{*}$ & {$[19.3,21.9]$} & $1.40^{* * *}$ & {$[1.25,1.56]$} & $0.62^{* * *}$ & {$[0.56,0.71]$} \\
\hline Excessive in free sugars & 3392 & 69.4 & {$[67.8,70.9]$} & $22.5^{*}$ & {$[21.1,23.9]$} & 0.96 & {$[0.86,1.08]$} & $0.69^{* * *}$ & {$[0.61,0.78]$} \\
\hline Excessive in saturated fats & 2658 & 65.5 & {$[63.7,67.3]$} & $19.4^{*}$ & {$[17.9,21.0]$} & $0.83^{* *}$ & {$[0.75,0.93]$} & $0.62^{* * *}$ & {$[0.55,0.70]$} \\
\hline Excessive in trans fats & 42 & 64.3 & {$[48.0,78.4]$} & $23.8^{*}$ & {$[12.1,39.5]$} & 1.08 & {$[0.57,2.10]$} & 1.21 & {$[0.57,2.51]$} \\
\hline Excessive in sodium & 3938 & 63.6 & {$[62.0,65.1]$} & $14.3^{*}$ & {$[13.2,15.4]$} & $0.59^{* * *}$ & {$[0.53,0.65]$} & $0.24^{* * *}$ & {$[0.22,0.27]$} \\
\hline Containing non-sugar sweeteners & 1484 & 94.9 & {$[93.6,95.9]$} & $18.6^{*}$ & {$[16.7,20.7]$} & $11.67^{* * *}$ & {$[9.14,14.88]$} & $0.54^{* * *}$ & {$[0.46,0.62]$} \\
\hline
\end{tabular}

Only includes products with claims. The proportion of products with health and nutrition claims in the regulatory scenario was estimated according to the nutrient profile thresholds of the new Mexican food labelling regulation (third stage). Proportion and Odds Ratio (OR) for products with health and nutrition claims according to the current scenario and regulatory scenario. For proportions, ${ }^{*}(P<0.05)$ indicates statistical significant different from current scenario. For Odds Ratio, **(P<0.01), ***(P<0.001) indicates statistical significance

the current scenario, products that were excessive in saturated fat (OR $0.83, P<0.01,95 \%$ CI $0.75-0.93$ ) and sodium (OR 0.59, $P<0.001,95 \%$ CI $0.53-0.65$ ) were less likely to display HNC compared to those products that were not excessive in these thresholds. In the regulatory scenario, we observed a significantly lower proportion of products with HNC for each threshold, mainly for products containing non-sugar sweeteners $(18.6 \% P<0.05$, 95\% CI 16.7-20.7) and those excessive in sodium (14.3\% $P<0.05,95 \%$ CI 13.2-15.4). In the regulatory scenario, the odds for displaying HNC were lower compared to the current scenario for each threshold.

\section{Discussion}

Of the 17,264 products in the Mexican market in 2017, $72 \%$ were ultra-processed, $33.8 \%$ displayed nutrition claims and $3.4 \%$ displayed health claims. About $45 \%$ of products had excess sodium and $40 \%$ had excess free sugars according to the regulation's thresholds. The new regulation would prevent about $40 \%$ of total products and $50 \%$ of ultra-processed food products with claims from displaying health and nutrition claims when the final thresholds go into effect.

The use of HNC on food products in Mexico is consistent with what has been found in other parts of the world; for example, in the UK, 32\% [24] of package products carry $\mathrm{HNC}$ and $29 \%$ in other European countries [36]. HNC could have considerable impacts on diet and thus health. This is because they provide information that may be of interest to consumers [37], especially those interested in improving their health [38].

However, HNC can be used for other purposes such as product marketing $[19,21]$. HNC may be more attractive to consumers who may perceive products that have them as being healthier, even if they are not. According to previous studies, foods and beverages with HNC are $75 \%$ more likely to be chosen compared to those without these claims [37]. In addition, improving food labelling and HNC regulations are recognized as public health interventions that can improve the food environment and have positive effects on nutritionrelated outcomes [39]. Several countries regulate the use of HNC on food products, however, these regulations generally do not include nutrient profiling systems and thus, it is still common to find HNC displayed on lesshealthy foods and beverages or ultra-processed products [40]. According to our results, the new Mexican FOPL regulation could improve consumers' dietary choices, as most less-healthy foods and beverages will be prevented from displaying HNC. This is an opportunity to improve the information on product packaging and avoid ambiguities for consumers; less-healthy foods and beverages will display warning labels but not HNC on FOPL, and conversely, healthier foods may display HNC but not warning labels.

The nutrient profile proposed in the Mexican regulation is based on the PAHO nutrient profile model, which excludes unprocessed foods from evaluation as they are considered healthier products, although there are some exceptions (for Mexico, the consumption of juices and whole fat milk is not recommended [41]). This study showed that a large proportion of ultraprocessed food products exceed the thresholds for calories, free sugars, and sodium, so they could be considered as less healthy. In Mexico, the contribution of these products is $30 \%$ of the population's total dietary calories and the consumption of free sugars, saturated fats, and sodium is higher among groups with the greatest intake of ultra-processed foods $[10,42]$. In addition, it means that the implementation of the Mexican warning label regulations will reduce the use of $\mathrm{HNC}$ mostly on these types of products.

According to a study conducted in the Mexican population, $22 \%$ reported using $\mathrm{HNC}$ on packaging to select 
their food and beverages at the point of sale. Until now, there was no strict regulation for the use of HNC in Mexico, so they could be displayed on the packaging regardless of nutritional quality [43]. The regulatory scenario has shown that HNC will be reduced in most less-healthy (ultra-processed) food products, so consumers will be able to make better-informed choices.

In the regulatory scenario, minimally processed or unprocessed foods may continue displaying HNC, so there would be no difference in the proportion of these foods with HNC between both scenarios. However, as previously mentioned, there are food groups not recommended by Mexican food-based dietary guidelines, such as fruit juice, which may still display HNC after the implementation of the regulation [41].

To our knowledge, this is the first regulation that includes a restriction of HNC on FOPL. In addition, it is also the first FOPL regulation to include the use of non-sugar sweeteners as a threshold. There is not enough evidence to describe the long-term effects of consumption of nonsugar sweeteners; however, the recommendations suggest not excluding possible negative effects [44]. However, the use of non-sugar sweeteners is different between countries. In a 2015 study that analyzed the prevalence of non-sugar sweeteners across four countries (Australia, Mexico, New Zealand and the United States), the highest proportion of products containing sweeteners other than sugar was reported for Mexico (11\% of all products) [45]. In our study, we found that products with non-sugar sweeteners generally displayed HNC related to the content of calories or sugar (highlighting their absence or low amount). A threshold related to non-sugar sweeteners will likely also prevent unnecessary unhealthy reformulations. In Chile, after the implementation of warning labels, the added sugar content in sugary drinks decreased, but the use of non-sugar sweeteners in these drinks increased [46]. They may display HNC but not warning labels, which could lead to a misperception about nutritional quality.

The Mexican regulation is based on the evidence and recommendations available for the development of effective FOPL [21, 37, 47-49]. However, this regulation has some limitations for HNC, for example, it does not cover health-related ingredient claims and general health claims (considered claims by INFORMAS), which could increase the use of these after regulation. In addition, health claims are restricted on the whole package while nutrition claims not related to excess thresholds can be displayed on the back of packaging. On the other hand, in Mexico there was an interest to regulate the use of health endorsements, a particular type of health claim in which different non-governmental health associations recommend or endorse the consumption of food and beverages for certain groups (for example, "Recommended by the Mexican Association of Pediatrics"). A study conducted in Mexico reported that more than $60 \%$ of foods and beverages with health endorsements were classified as less-healthy and endorsements were frequently found in sweetened beverages and sweet snacks; most of the organizations that endorsed these products were professional and independent diabetes and nutrition groups associated with the food industry [50].

\section{Strengths and limitations}

The results of this study provide an approximation to what could be observed after the implementation of the regulation. We also describe the prevalence of products that show HNC, so they could be used as a baseline measure for future evaluations of this regulation. However, the regulatory scenario proposed in this study is conservative, so other possible effects of the new Mexican regulation are not considered, such as changes in the avail of healthier foods (or reformulated foods) that utilize HNC. Another possible effect is an increase in claims not considered in the new regulation on lesshealthy foods such as other claims or health-related ingredient claims. These hypotheses may be demonstrated after April 2021, with the mandatory regulation of HNC and other packaging elements (such as characters or promotions) on less-healthy foods.

\section{Conclusion}

The new Mexican front-of-pack labelling regulation is the first in the world to include restrictions on positioning of HNC on FOPL and this study estimated that the new regulation would prevent most less-healthy processed and ultra-processed foods from displaying HNC, in particular those containing non-sugar sweeteners. This is important as a reduction in HNC on less-healthy products may improve the effectiveness of the warning labels for consumers.

\section{Abbreviations}

NCDs: Non-communicable diseases; HNC: Health and nutrition claims; FOPL: Front-of-pack labelling; PAHO: Pan American health organization; INFORMAS: International network of food and obesity/non-communicable diseases research, monitoring and action support

\section{Supplementary Information}

The online version contains supplementary material available at https://doi. org/10.1186/s12966-021-01148-1.

Additional file 1. Definitions and taxonomy of claims.

Additional file 2. Missing data. This document contains the specifications, definitions, examples and taxonomy for the classification of claims, based on the protocols of the International Network for Food and Obesity / noncommunicable Diseases Research, Monitoring and Action Support.

\section{Acknowledgements}

The authors thank the entire team that contributed with the data collection and the classification of claims. 


\section{Authors' contributions}

The original idea was provided by LTM and SV. LTM wrote the research protocol. LTM, SB and team collected the information. CCC, SV and LTM wrote the manuscript of this study. CCC analyzed and interpreted the results. All authors read and approved the final version of the manuscript.

\section{Funding}

The financial support was used for the collection and treatment of data, and was provided by Bloomberg Philanthropies (grant number 43003) and the International Development Research Centre (grant number 1534). The funders had no role in the design, analysis, or writing of this article.

\section{Availability of data and materials}

The datasets used and analyzed during the current study are not publicly available. Data are however available upon reasonable request and with permission of the corresponding author.

\section{Declarations}

\section{Ethics approval and consent to participate}

This study was approved by the Research, Ethics and Biosafety Committees of the Mexican National Institute of Public Health (approved number: 1530). This study does not report or involve the use of any animal or human data.

\section{Consent for publication}

Not applicable.

\section{Competing interests}

The authors declare that they have no competing interests.

\section{Author details}

${ }^{1}$ Centro de Investigación en Nutrición y Salud, Instituto Nacional de Salud Pública, Universidad No. 655, Colonia Santa María Ahuacatitlán, Cerrada Los Pinos y Caminera. C.P, Cuernavaca, Morelos 62100, Mexico. ${ }^{2}$ Department of Epidemiology and Statistics, School of Population health, The University of Auckland, Auckland, New Zealand.

Received: 9 August 2020 Accepted: 2 June 2021

\section{Published online: 10 June 2021}

\section{References}

1. Benziger CP, Roth GA, Moran AE. The global burden of disease study and the preventable burden of NCD. Glob Heart 2016;1 1:393-397. Available from: http://dx.doi.org/https://doi.org/10.1016/.gheart.2016.10.024, 4

2. Afshin A, Sur PJ, Fay KA, Cornaby L, Ferrara G, Salama JS, et al. Health effects of dietary risks in 195 countries, 1990-2017: a systematic analysis for the global burden of disease study 2017. Lancet. 2019;393(10184):1958-72. https://doi.org/10.1016/50140-6736(19)30041-8.

3. Instituto Nacional de Salud Pública. Encuesta Nacional de Salud y Nutrición [Internet]. 2018 [cited 2020 Jun 7]. p. 47. Available from: https://ensanut.insp.mx/

4. Rojas-Martínez R, Basto-Abreu A, Aguilar-Salinas CA, Zárate-Rojas E, Villalpando S, Barrientos-Gutiérrez T. Prevalencia de diabetes por diagnóstico médico previo en México. Salud Publica Mex. 2018;60(3, may-jun):224. https://doi.org/10.21149/8566.

5. Pan American Health Organization. Nutrient Profile Model [Internet]. Washington, DC; 2016 [cited 2019 Feb 9]. p. 6. Available from: http://www. euro.who.int/en/health-topics/disease-prevention/nutrition/publications/201 5/who-regional-office-for-europe-nutrient-profile-model-2015

6. Monteiro CA, Cannon G, Moubarac JC, Levy RB, Louzada MLC, Jaime PC. The UN Decade of Nutrition, the NOVA food classification and the trouble with ultra-processing. Public Health Nutr. 2018;21:5-17. https://doi.org/10.1 017/S1368980017000234

7. Luiten CM, Steenhuis IHM, Eyles H, Mhurchu CN, Waterlander WE. Ultraprocessed foods have the worst nutrient profile, yet they are the most available packaged products in a sample of New Zealand supermarkets. Public Health Nutr. 2014;19:530-8.

8. Monteiro CA, Cannon G, Levy RB, Moubarac JC, Jaime P, Martins AP. NOVA. The star shines bright. Food Clasif Public Heal World Nutr. 2016;7:28-38.
9. Monteiro CA, Cannon G, Levy RB, Moubarac JC, Louzada MLC, Rauber F, et al. Ultra-processed foods: what they are and how to identify them. Public Health Nutr. 2019;22(5):936-41. https://doi.org/10.1017/S1368980018003762.

10. Marrón-Ponce JA, Flores M, Cediel G, Monteiro CA, Batis C. Associations between consumption of ultra-processed foods and intake of nutrients related to chronic non-communicable diseases in Mexico. J Acad Nutr Diet; 2019; Available from: https://doi.org/https://doi.org/10.1016/j.jand.2 019.04.020

11. World Health Organization. Diet, nutrition and the prevention of chronic diseases [Internet]. WHO Tech Rep Ser. 2002;916:54-60. Available from: https://apps.who.int/iris/bitstream/handle/10665/42665/WHO_TRS_916. pdf? sequence $=1$. [cited 2019 Aug 1].

12. World Health Organization. Global Strategy on diet, physical activity and health [Internet]. 2002 [cited 2019 Aug 13]. p. 1-260. Available from: https://apps.who.int/iris/bitstream/handle/10665/43035/9241592222_eng. pdf? sequence $=1$

13. Campos S, Doxey J, Hammond D. Nutrition labels on pre-packaged foods: a systematic review. Public Health Nutr. 2011;14(8):1496-506. https://doi.org/1 $0.1017 /$ S1368980010003290.

14. Cowburn G, Stockley L. Consumer understanding and use of nutrition labelling: a systematic review. Public Health Nutr. 2005;8(1):21-8. https://doi. org/10.1079/PHN2004666.

15. Vargas-Meza J, Jáuregui A, Pacheco-Miranda S, Contreras-Manzano A, Barquera S. Front-of-pack nutritional labels: acceptability and subjective understanding in Mexican consumers. PLoS One. 2019;19:1-16.

16. Shangguan S, Afshin A, Shulkin M, Ma W, Micha R, Imamura F, et al. A metaanalysis of food labeling effects on consumer diet behaviors and industry practices. Am J Prev Med. 2020;56:300-14.

17. Neal B, Sacks G, Swinburn B, Vandevijvere S, Dunford E, Snowdon W, et al. Monitoring the levels of important nutrients in the food supply. Obes Rev. 2013;14:49-58. https://doi.org/10.1111/obr.12075.

18. Silayoi P, Speece M. Packaging and purchase decisions: an exploratory study on the impact of involvement level and time pressure. Br Food J. 2004; 106(8):607-28. https://doi.org/10.1108/00070700410553602.

19. van Buul JV, FJPH B. Nutrition and health claims as marketing tools. Crit Rev Food Sci Nutr. 2015;55:1552-60.

20. Oostenbach LH, Slits E, Robinson E, Sacks G. Systematic review of the impact of nutrition claims related to fat, sugar and energy content on food choices and energy intake. BMC Public Health. 2019;19:1-11.

21. Chandon P. How package design and packaged-based marketing claims lead to overeating. Appl Econ Perspect Policy. 2013;35(1):7-31. https://doi. org/10.1093/aepp/pps028.

22. Wills JM, Storcksdieck Genannt Bonsmann S, Kolka M, Grunert KG. European consumers and health claims: attitudes, understanding and purchasing behaviour. Proc Nutr Soc. 2012;71(2):229-36. https://doi.org/10.1017/S002 9665112000043.

23. Al-Ani HH, Devi A, Eyles H, Swinburn B, Vandevijvere S. Nutrition and health claims on healthy and less-healthy packaged food products in New Zealand. Br J Nutr. 2016;116(6):1087-94. https://doi.org/10.1017/S000711451 6002981.

24. Kaur A, Scarborough P, Matthews A, Payne S, Mizdrak A, Rayner M. How many foods in the UK carry health and nutrition claims, and are they healthier than those that do not? Public Health Nutr. 2016;19(6):988-97. https://doi.org/10.1017/S1368980015002104.

25. Lalor F, Kennedy J, Flynn MAT, Wall PG. A study of nutrition and health claims - a snapshot of whats on the Irish market. Public Health Nutr. 2010; 13(05):704-11. https://doi.org/10.1017/S1368980009991613.

26. Rodrigues VM, Rayner M, Fernandes AC, De Oliveira RC, Da Costa Proença RP, Fiates GMR. Comparison of the nutritional content of products, with and without nutrient claims, targeted at children in Brazil. Br J Nutr. 2016; 115(11):2047-56. https://doi.org/10.1017/S0007114516001021.

27. Rayner M, Wood A, Lawrence M, Mhurchu CN, Albert J, Barquera S, et al. Monitoring the health-related labelling of foods and non-alcoholic beverages in retail settings. Obes Rev. 2013;14:70-81. https://doi.org/1 0.1111/obr.12077.

28. Vandevijvere S, Rayner M. INFORMAS Food Labelling Module - Monitoring health-related labeling and promotional characters/premium offers on foods and non-alcoholic beverages in retail outlets. Auckland, New Zealand: The University of Auckland; 2017. p. 1-61.

29. Federal Register of Legislation. Australia New Zealand Food Standards Code - Standard 1.2.7 - Nutrition, Health and Related Claims [Internet]. 2013 [cited 
2019 Aug 9]. Available from: https://www.legislation.gov.au/Details/F201 $6 \mathrm{C} 00082$

30. Rayner M. Nutrient profiling for regulatory purposes. Proc Nutr Soc. 2017; 76(3):230-6. https://doi.org/10.1017/S0029665117000362

31. Tolentino-Mayo L, Sagaceta-Mejía J, Cruz-Casarrubias C, Ríos-Cortázar V, Jauregui A, Barquera S. Understanding and use of the front-of-pack guideline daily amounts nutritional labeling of industrialized food and beverages in Mexico. Salud Publica Mex. 2020;62(6, Nov-Dic):786-97. https:// doi.org/10.21149/11568.

32. Secretaría de Economía. MODIFICACIÓN a la Norma Oficial Mexicana NOM051-SCFI/SSA1-2010, Especificaciones generales de etiquetado para alimentos y bebidas no alcohólicas preenvasados-Información comercial y sanitaria, publicada el 5 de abril de 2010 [Internet]. 2020 [cited 2020 Apr 2]. Available from: http://dof.gob.mx/2020/SEECO/NOM_051.pdf

33. Contreras-Manzano A, Jáuregui A, Velasco-Bernal A, Vargas-Meza J, Rivera $J A$, Tolentino-Mayo L, et al. Comparative analysis of the classification of food products in the mexican market according to seven different nutrient profiling systems. Nutrients. 2018;10(6). https://doi.org/10.3390/nu10060737.

34. Paredes I, Silva E. Estimación de la esperanza de vida a nivel municipal y por marginación sociodemográfica: una aplicación del método de Swanson para el caso de México, 2010. Estud Demogr Urbanos Col Mex. 2017;32:97-129.

35. Opportimes. Walmart tiene una participación de $68 \%$ en el mercado de México [Internet]. 2017 [cited 2019 Feb 9]. Available from: https:/www. opportimes.com/walmart-una-participacion-68-mercado-mexico/

36. Kaur A, Scarborough P, Hieke S, Kusar A, Pravst I, Raats M, Rayner M The nutritional quality of foods carrying health-related claims in Germany, the Netherlands, Spain, Slovenia and the United Kingdom. Eur J Clin Nutr [internet]. Nat Publ Group; 2016;70:1388-1395. Available from: http://dx.doi. org/https://doi.org/10.1038/ejcn.2016.114, 12

37. Kaur A, Scarborough P, Rayner M. A systematic review, and meta-analyses, of the impact of health-related claims on dietary choices. Int J Behav Nutr Phys Act. 2017;14:1-17.

38. Steinhauser J, Janssen $M$, Hamm U. Who buys products with nutrition and health claims? A purchase simulation with eye tracking on the influence of consumers' nutrition knowledge and health motivation. Nutrients. 2019;11:1-20.

39. Roy R, Kelly B, Rangan A, Allman-Farinelli M. Food environment interventions to improve the dietary behavior of young adults in tertiary education settings: a systematic literature review. J Acad Nutr Diet; 2015; 115:1647-1681.e1. Available from: http://dx.doi.org/https://doi.org/10.1016/j. jand.2015.06.380

40. Pulker CE, Scott JA, Pollard CM. Ultra-processed family foods in Australia: nutrition claims, health claims and marketing techniques. Public Health Nutr. 2018;21 (1):38-48. https://doi.org/10.1017/S1368980017001148.

41. Rivera J, Muñoz-Hernández O, Rosas-Peralta M, Aguilar-Salinas C, Popkin B, Willett W. Beverage consumption for a healthy life: recommendations for the Mexican population. Salud Publica Mex. 2008;50(2):173-95. https://doi. org/10.1590/S0036-36342008000200011.

42. Marrón-Ponce JA, Sánchez-Pimienta TG, Da Costa Louzada ML, Batis C. Energy contribution of NOVA food groups and sociodemographic determinants of ultra-processed food consumption in the Mexican population. Public Health Nutr. 2018;21(1):87-93. https://doi.org/10.1017/S13 68980017002129.

43. Tolentino-Mayo L, Patiño SRG, Bahena-Espina L, Ríos V, Barquera S. Knowledge and use of nutrient labelling of industrialized foods and beverages in Mexico. Salud Publica Mex. 2018;60(3, may-jun):328-37. https:// doi.org/10.21149/8825.

44. Toews I, Lohner S, Küllenberg De Gaudry D, Sommer H, Meerpohl JJ. Association between intake of non-sugar sweeteners and health outcomes: Systematic review and meta-analyses of randomised and non-randomised controlled trials and observational studies. BMJ. 2019;364:1-12.

45. Dunford EK, Taillie LS, Miles DR, Eyles H, Tolentino-Mayo L, Ng SW. Nonnutritive sweeteners in the packaged food supply —an assessment across 4 countries. Nutrients. 2018;10:1-13.

46. Quitral V, Arteaga J, Rivera M, Galleguillos J, Valdés I. Comparison of sugar and non- caloric sweetener content in beverages before and after implementing Chilean law 20.606. Comparison. 2019:46:245-53.

47. Mozaffarian D, Angell SY, Lang T, Rivera JA. Role of government policy in nutrition-barriers to and opportunities for healthier eating. BMJ. 2018;361:1-11.
48. Khandpur N, de Morais SP, Mais LA, Bortoletto Martins AP, Spinillo CG, Garcia MT, et al. Are front-of-package warning labels more effective at communicating nutrition information than traffic-light labels? A randomized controlled experiment in a Brazilian sample. Nutrients. 2018;10:1-15.

49. Jones A, Neal B, Reeve B, Ni Mhurchu C, Thow AM. Front-of-pack nutrition labelling to promote healthier diets: current practice and opportunities to strengthen regulation worldwide. BMJ Glob Heal. 2019;4:1-16.

50. Cruz-Casarrubias C, Munguía A, Tolentino-Mayo L, Barquera S. Use of health and nutritional endorsements in unhealthy food and beverages in Mexico: opportunity to avoid misleading information. Salud Publica Mex. 2020;62:265-6.

\section{Publisher's Note}

Springer Nature remains neutral with regard to jurisdictional claims in published maps and institutional affiliations.
Ready to submit your research? Choose BMC and benefit from:

- fast, convenient online submission

- thorough peer review by experienced researchers in your field

- rapid publication on acceptance

- support for research data, including large and complex data types

- gold Open Access which fosters wider collaboration and increased citations

- maximum visibility for your research: over $100 \mathrm{M}$ website views per year

At BMC, research is always in progress.

Learn more biomedcentral.com/submissions 